\title{
Shape-memory actuators based on dual-curing thiol-acrylate-epoxy thermosets
}

\author{
C. Russo ${ }^{1}$, X. Fernandez-Francos ${ }^{2 *}$, S. De la Flor ${ }^{1}$ \\ ${ }^{1}$ Department of Mechanical Engineering, Universitat Rovira i Virgili, Av. Països Catalans 26, 43007 Tarragona, Spain \\ ${ }^{2}$ Thermodynamics Laboratory, ETSEIB, Universitat Politècnica de Catalunya, Av. Diagonal 647, 08028 Barcelona, Spain
}

Received 6 April 2020; accepted in revised form 20 June 2020

\begin{abstract}
In this work, new shape-memory thermosets have been developed using a thiol-acrylate-epoxy dual-curing system. A previously studied system has been successfully modified, introducing different amounts of tri(2,3-epoxypropyl)isocyanurate (ISO) and bisphenol A glycerolate (1 glycerol/phenol) diacrylate (BAGA) in order to enhance the thermomechanical properties and the glass transition temperature of the final materials. Preliminary studies on the curing process proved that the curing process is not affected, and the critical ratio remains unchanged. Glass transition temperatures and thermomechanical properties were successfully improved, extending the applicability of these thermosets to the field of soft-actuator. Shape-memory behavior was comprehensively investigated in unconstrained, fully and partially constrained conditions. Unconstrained experiment results showed excellent shape fixation and recovery, coupled with a fast recovery process. On the other hand, fully and partially constrained recovery experiments evidenced optimal performances obtained by the combination of both high crosslinking density and high deformability in the programming stage. Considerably high values of recovery stress (up to $7 \mathrm{MPa}$ ) and work output (up to $1300 \mathrm{~kJ} / \mathrm{m}^{3}$ ) were found confirming the high potentiality of these dual-cured thermosets in the field of soft-actuation.
\end{abstract}

Keywords: thermosetting resins, dual-curing, actuator, shape-memory, recovery stress

\section{Introduction}

Shape-memory polymers (SMPs) are a class of smart materials capable of storing a temporarily deformed shape and subsequentially recover their original permanent shape under the application of an external stimulus [1]. They represent one of the most extensively investigated mechanical active materials due to their potential applications in a large variety of fields such as aerospace industry, soft-robotics, biomedicine, and sensors [2-5]. The shape-memory effect (SME) is usually thermally activated because it is easier to operate, but it can also be induced by light, magnetic field, or an electrical current [6-8].

Recently, many studies have focused on crosslinked thermosets reporting excellent shape-memory properties enabling the use of SMPs in highly mechanical demanding applications [9-11]. Among them, epoxybased shape-memory polymers have been widely used thanks to their optimal mechanical, thermal, electrical, and optical properties. On the other hand, their rigid structure and brittle behavior with small elongation at break have always represented important drawbacks that have limited their uses. Nowadays, a lot of different strategies to overcome this issue are available in the literature, relying on both the design of the material $[12,13]$ and the optimization of programming conditions $[14,15]$. The combination of these two strategies allowed improving both the deformability and ultimate strength of SMPs, as demonstrated by the results obtained by Belmonte and coworkers [16, 17].

More flexible materials with lower glass transition temperature $T_{\mathrm{g}}$ can be obtained using acrylate 
monomers. Acrylate based shape-memory thermosets were also deeply investigated during years, efforts being directed at the understanding of the effect of the network design on their thermal, mechanical, and shape memory properties [18-20]. One example can be found in Dhulst et al. [21], who combined both thiol-epoxy and thiol-acrylate network in phase-separated networks with good mechanical properties and interesting shape-memory properties.

Another interesting way to combine acrylate and epoxy is a dual-curing procedure in which a combination of two distinct crosslinking reactions, taking place simultaneously or sequentially, form the final network [22]. The combination of two sequential curing reactions makes it possible to obtain intermediate materials that maintain the ability to react upon application of a second stimulus, leading to fully cured materials with a new set of properties. In previous works, a promising epoxy-acrylate dual-curing system, based on the combination of thiol-acrylate Michael addition (first curing reaction) and thiolepoxy addition (second curing reaction), was developed and characterized [23, 24]. It was found that the curing process was almost sequential, with very little overlapping of both reactions at room temperature and remarkable intermediate stability. Mechanical and thermo-mechanical characterization of final thermosets revealed that a wide range of properties could be obtained upon variation of the ratio between acrylate and thiols group $\left(r_{\mathrm{a}}\right)$. An interesting combination of the properties of the two networks was obtained with $r_{\mathrm{a}}=0.6$, resulting in final materials with high deformation at break, with a gelled intermediate state. Moreover, qualitative tests showed promising shapememory properties in terms of recovery and fixation ratio together with high material processability in the intermediate stage and during the programming step. However, the generally low $T_{\mathrm{g}}$ of the final thermosets and the poor thermo-mechanical properties in the rubbery state strongly limited their use as SMPs for mechanical actuators. An interesting application of sequential dual-curing systems is the preparation of multi-layered assemblies incorporating liquid crystal elastomers (LCE), which can act as free-standing thermally reversible actuators [25]. Thermal actuation of such devices can be triggered by the isotropization temperature of the LCE component, and it is affected by the thermomechanical properties and relaxation dynamics of the thermosetting component.
In this work, we explore the possibility of improving thermomechanical properties of sequential dual-curing materials based on thiol-acrylate and thiol-epoxy chemistry by modification of both the acrylate and epoxy components. Thermosets were prepared at the critical acrylate:thiol ratio $r_{\mathrm{a}}=r_{\mathrm{c}}=0.5$ in order to produce a gelled material at the very end of the first curing stage and a final material with a $T_{\mathrm{g}}$ as high as possible [24]. The effect of the new components on the dual-curing kinetic was evaluated by differential scanning calorimetry (DSC) in order to prove that the sequential character of the system is preserved. The first curing stage was also monitored through rheological analysis in order to confirm that no alteration of critical ratio was caused by the incorporation of the new components. Dynamic mechanical analysis (DMA) was performed in order to evaluate the effect of the new compositions on the network relaxation and thermomechanical properties. Best materials were selected, and their shape-memory behavior was tested in three different recovery situations (unconstrained, partially-constrained and fully-constrained) in order to evaluate their capability to generate work or stress during the recovery process.

\section{Materials and methods}

\subsection{Materials}

Different mixtures of tricyclo[5.2.1.02,6]decanedimethanol diacrylate (TCDDA, Sigma-Aldrich, St. Louis, USA, $152.2 \mathrm{~g} / \mathrm{eq}$ ) and bisphenol A glycerolate (1 glycerol/phenol) diacrylate (BAGA, SigmaAldrich, $242.3 \mathrm{~g} / \mathrm{eq}$ ) were prepared using 10,30 and $50 \mathrm{wt} \%$ of BAGA (i.e. 20:80 wt $\%$ BAGA:TCDDA). A commercial epoxy resin, diglycidyl ether of bisphenol A (DGEBA, EPIKOTETM Resin 828, Hexion specialty chemicals, Columbus, USA) with an epoxy equivalent weight of $187 \mathrm{~g} / \mathrm{eq}$ was used as the main epoxy resin. In addition, a tri(2,3-epoxypropyl)isocyanurate (ISO, Sigma-Aldrich) with an epoxy equivalent weight of $99.09 \mathrm{~g} / \mathrm{eq}$ was used as modifier in different proportions: 10,30 and $50 \mathrm{wt} \%$ (i.e. $20: 80 \mathrm{wt} \%$ ISO:DGEBA). Pentaerythritol tetrakis(3-mercaptopropionate) (S4, Sigma-Aldrich), with a molecular weight per thiol equivalent unit of $122.17 \mathrm{~g} / \mathrm{e}$, was used as thiol crosslinker maintaining the ratio between acrylate and thiol groups fixed at $0.5\left(r_{\mathrm{a}}=\right.$ 0.5). 4-(N,N-dimethylamino)pyridine (DMAP, Fluka, Seelze, Germany) used at $0.05 \mathrm{phr}$ to catalyze both 


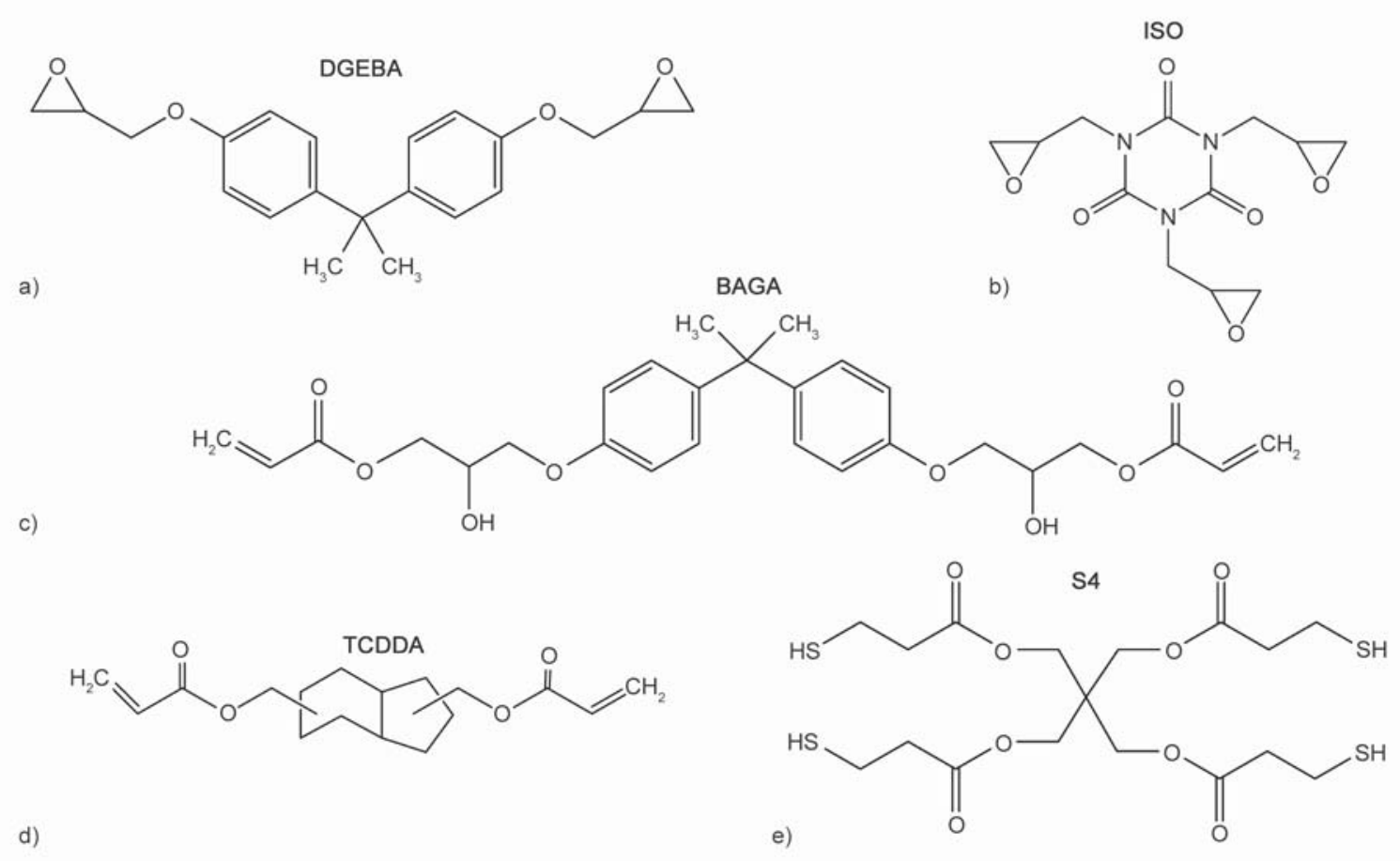

Figure 1. Schematic representation of the system components: (a) diglycidyl ether of bisphenol A (DGEBA); (b) tri(2,3epoxypropyl)isocyanurate (ISO); (c) bisphenol A glycerolate (1 glycerol/phenol) diacrylate (BAGA); (d) tricyclo[5.2.1.02,6]decanedimethanol diacrylate (TCDDA); (e) Pentaerythritol tetrakis(3-mercaptopropionate) (S4).

curing reactions. Figure 1 shows the structure of the different reagents employed in this work.

First of all, epoxy and acrylate mixtures were prepared separately, homogenizing the components, respectively, at 150 and $70^{\circ} \mathrm{C}$ under magnetic stirring. After that, selected quantities of both mixtures were mixed with S4 and catalyst and manually stirred at room temperature. All samples were cured at $40^{\circ} \mathrm{C}$ for $2 \mathrm{~h}\left(1^{\text {st }}\right.$ step $), 80^{\circ} \mathrm{C}$ for $3 \mathrm{~h}\left(2^{\text {nd }}\right.$ step $)$, and $100^{\circ} \mathrm{C}$ for $1 \mathrm{~h}$ (post-curing). Samples in Table 1 were coded with two number indicating, respectively, the percentage of ISO and the percentage of BAGA (i.e. 2050 indicates the 20:50 mixture of DGEBA and ISO together with the 50:50 mixture of BAGA and

Table 1. Composition of the formulation under investigation.

\begin{tabular}{|l|c|c|c|c|c|}
\hline $\begin{array}{c}\text { Formula } \\
\text { tion }\end{array}$ & $\begin{array}{c}\text { TCDDA } \\
{[\mathbf{e q} \%]}\end{array}$ & $\begin{array}{c}\text { BAGA } \\
{[\mathbf{e q} \%]}\end{array}$ & $\begin{array}{c}\text { DGEBA } \\
{[\mathbf{e q} \%]}\end{array}$ & $\begin{array}{c}\text { ISO } \\
{[\mathbf{e q} \%]}\end{array}$ & $\begin{array}{c}\text { S4 } \\
{[\mathbf{e q} \%]}\end{array}$ \\
\hline NN & 25.00 & - & 25.00 & - & 50.00 \\
\hline N10 & 23.72 & 1.66 & 24.88 & - & 49.75 \\
\hline N30 & 20.37 & 5.48 & 24.70 & - & 49.45 \\
\hline N50 & 15.98 & 10.04 & 24.68 & - & 49.30 \\
\hline $10 \mathrm{~N}$ & 24.91 & - & 20.90 & 4.38 & 49.81 \\
\hline $20 \mathrm{~N}$ & 24.83 & - & 17.33 & 8.17 & 49.67 \\
\hline $50 \mathrm{~N}$ & 24.78 & - & 8.89 & 16.77 & 49.56 \\
\hline 2050 & 15.88 & 9.97 & 17.10 & 8.07 & 48.98 \\
\hline 5050 & 15.84 & 9.95 & 8.77 & 16.55 & 48.88 \\
\hline
\end{tabular}

TCDDA while 5050 indicates the 50:50 mixture of DGEBA and ISO together with the 50:50 mixture of BAGA and TCDDA). Formulation with no percentage of BAGA and ISO was coded NN, where N stands for the use only TCDDA or DGEBA.

\subsection{Characterization techniques}

\subsubsection{Curing process characterization}

The effect of different proportions of BAGA and ISO on the dual-curing process was evaluated by differential scanning calorimetry (DSC) in a Mettler Toledo (Greifensee, Switzerland) DSC-3+ apparatus, calibrated using an In standard (heat flow calibration) and an In-Pb-Zn standard (T calibration). Dynamic studies between 0 and $200^{\circ} \mathrm{C}$ with a heating rate of $10^{\circ} \mathrm{C} / \mathrm{min}$ were performed to characterize the curing process.

The dual-curing process was monitored using a rheometer AR-G2 TA Instruments, (New Castle, USA), equipped with an electrically heated plate device (EHP) and $20 \mathrm{~mm}$ parallel plate geometry. The evolution of the storage $\left(G^{\prime}\right)$ and loss modulus $\left(G^{\prime \prime}\right)$ was monitored through dynamo-mechanical experiments at $40^{\circ} \mathrm{C}$ for $3 \mathrm{~h}$. The oscillation amplitude was set at $0.2 \%$ and the frequencies at $0.5,1.75$, and $3 \mathrm{~Hz}$. Gel point was determined as the $\tan \delta$ crossover at the three different frequencies. 


\subsubsection{Thermomechanical characterization} A DMA Q800 (TA Instruments New Castle, USA) equipped with a 3-point-bending clamp (with a span of $15 \mathrm{~mm}$ ) was used. The experiments were performed at $3{ }^{\circ} \mathrm{C} / \mathrm{min}$ heating rate, from 0 to $120^{\circ} \mathrm{C}$, at $1 \mathrm{~Hz}$ and $0.1 \%$ of strain. Prismatic rectangular samples were thoroughly polished until homogeneous dimensions of about $30 \times 5.5 \times 2.5 \mathrm{~mm}^{3}$ were obtained. The glass transition temperature $T_{\mathrm{g}}$ and the full width at half maximum (FWHM) were determined from the $\tan \delta$ curve peak. The values of storage modulus $E^{\prime}$ below and above glass transition were evaluated. The $T_{\mathrm{g}}^{\mathrm{E}^{\prime}}$ was calculated as the onset point of the drop in storage modulus upon mechanical relaxation of the network. A peak in the deformability is obtained at this temperature coinciding with the onset of the mechanical relaxation $[14,15]$.

The flexural modulus $(E)$ of final materials was determined with the same apparatus by means of a force ramp at a constant rate of $1 \mathrm{~N} / \mathrm{min}$ in controlledforce mode. The slope $(m)$ within the linear zone of the force-displacement curve was obtained. $E$ was calculated in accordance with Equation (1):

$E=\frac{L^{3} m}{4 w t^{3}}$ where $L$ is the support span, and $w$ and $t$ are the widths and the thickness of the test sample, respectively.

\subsubsection{Mechanical characterization}

The mechanical properties in tension at $T_{\mathrm{g}}^{\mathrm{E}^{\prime}}$ were measured using a DMA Q800 (TA Instruments, New Castle, USA) equipped with a film-tension clamp in force-controlled mode. Prismatic rectangular samples of about $20 \times 3.5 \times 0.4 \mathrm{~mm}^{3}$ were tested until break at $T_{\mathrm{g}}^{\mathrm{E}^{\prime}}$ with a force rate of $1 \mathrm{~N} / \mathrm{min}$. Stress and deformation at break were evaluated together with the values of tensile modulus $\left(E_{\mathrm{t}}\right)$ for all samples. In addition, the strain energy density (SED) was calculated as the area under the stress-strain curve.

\subsubsection{Shape-memory characterization}

The shape-memory properties of prismatic rectangular samples of about $20 \times 3.5 \times 0.4 \mathrm{~mm}^{3}$ were measured using a DMA Q800 (TA Instruments, New Castle, USA) with a film-tension clamp in force-controlled mode. Three different shape-memory experiments were performed: free-recovery test (Figure 2b), fully-constrained recovery test (Figure 2c), and partially-constrained recovery test (Figure 2d). Each test was carried out following customized methods consisting of various steps, as described in Figure 2.
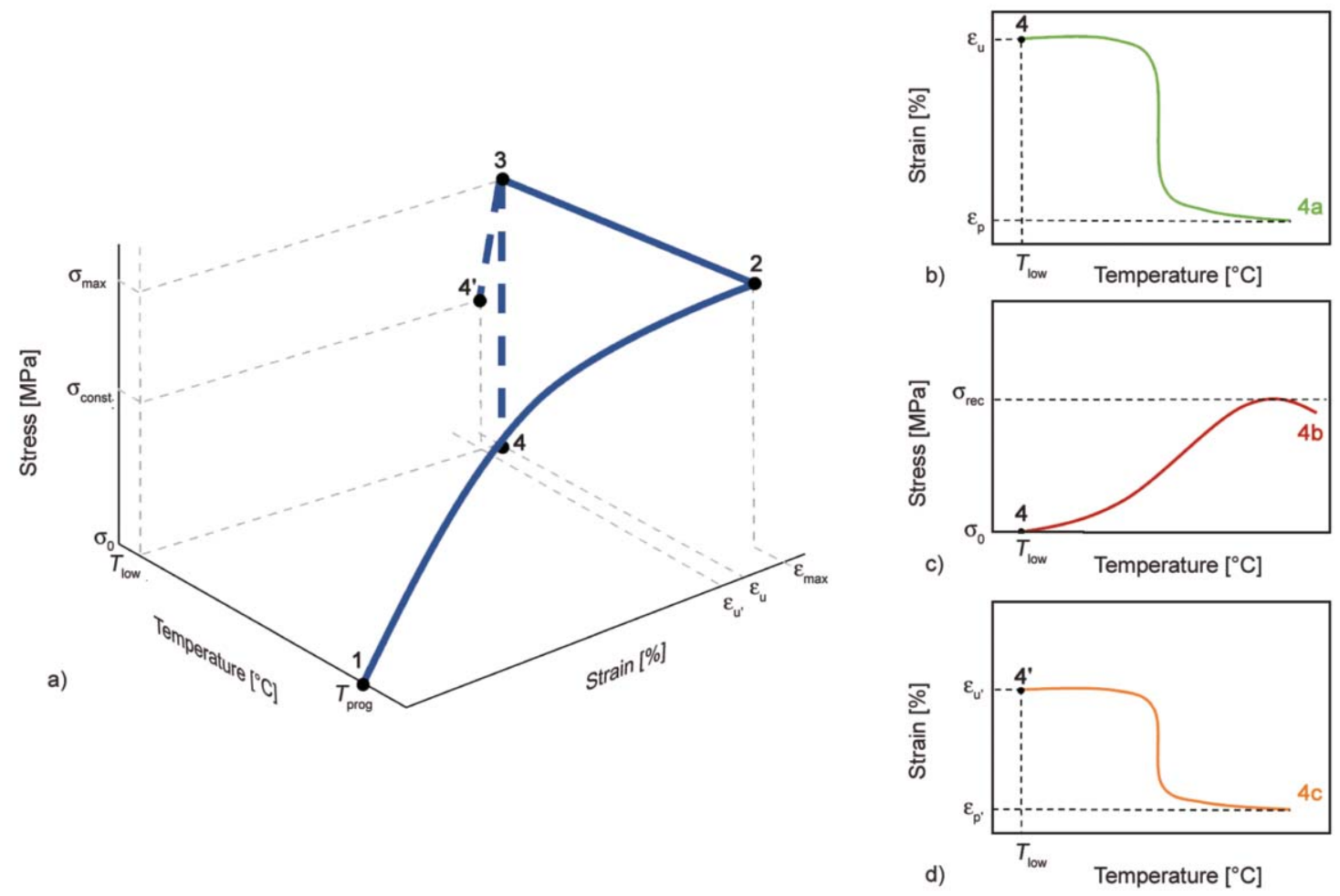

Figure 2. Schematic representation of the shape-memory tests: (a) thermomechanical programming, (b) free recovery experiment, (c) constrained recovery experiment, (d) partially-constrained recovery experiment. 
In all cases, there is a programming of the sample (path 1-2-3 in Figure 2a) prior to the shape-memory analysis. Samples were heated to the programming temperature $\left(T_{\text {prog }}\right)$ at which the sample was deformed, applying a prescribed value of maximum stress $\sigma_{\max }$, reaching a value of maximum deformation $\varepsilon_{\max }$ (path 1-2). Afterward, sample deformation was fixed by rapidly cooled down to a fixation temperature ( $T_{\text {low }}$ ) well below its $T_{\mathrm{g}}$ (path 2-3).

For the free-recovery test, the stress was released $\left(\sigma_{0}=0\right)$ after cooling down, and the deformation was stabilized at an ultimate deformation $\varepsilon_{\mathrm{u}}$, slightly lower than $\varepsilon_{\max }$. The permanent shape was recovered by heating the programmed sample at $3{ }^{\circ} \mathrm{C} / \mathrm{min}$ to a temperature above $T_{\mathrm{g}}\left(T_{\text {recovery }}\right)$ (path $\left.4 \mathrm{a}\right)$. The recovery process ended with a deformation value of $\varepsilon_{\mathrm{p}}$, which represents the amount of deformation that the sample is not able to recover. At this point a new cycle began by adjusting the temperature again to $T_{\text {prog. }}$. Three consecutive cycles were performed for each sample. In order to quantify the shape-memory properties of our materials, shape-recovery ratio $\left(R_{\mathrm{r}}\right)$ and shape-fixation ratio $\left(R_{\mathrm{f}}\right)$ were calculated using Equation (2) and (3):

$$
\begin{aligned}
& R_{\mathrm{r}}[\%]=\frac{\varepsilon_{\max }-\varepsilon_{\mathrm{p}}}{\varepsilon_{\max }} \cdot 100 \\
& R_{\mathrm{f}}[\%]=\frac{\varepsilon_{\mathrm{u}}}{\varepsilon_{\text {max }}} \cdot 100
\end{aligned}
$$

These two parameters quantify the ability of the material, respectively, to recover its original shape and to fix a temporary one. Both values were calculated as the average of all the obtained values after each cycle. The maximum stress applied during the path $1-2$ was $75 \%$ of the stress at break $\left(\sigma_{\max }=0.75 \cdot \sigma_{\text {break }}\right)$ in order to perform a comparative study with the same load level for each sample. Samples were programmed at $T_{\mathrm{g}}^{\mathrm{E}^{\prime}}$ since it is widely reported as the most effective programming condition [14-16]. To ensure a complete recovery process, samples were heated to $T_{\text {recovery }}=T_{\mathrm{g}}+20^{\circ} \mathrm{C}$, while $T_{\text {low }}=10^{\circ} \mathrm{C}$ was chosen as fixation temperature as a result of the fixation tests presented in the previous section. Loading and unloading force ramp were carried out at $1 \mathrm{~N} / \mathrm{min}$.

Fully-constrained recovery is aimed to compute the recovery stress that our materials are able to generate. To do that, samples were heated while the deformation after the unloading $\varepsilon u$ was kept constant (path $4 \mathrm{~b})$. As a result, the stress increased as the temperature increased, reaching a maximum value orec. All samples were programmed at the same level of stress $\left(\sigma_{\max }=8 \mathrm{MPa}\right)$ selected within the failure limit of all samples.

The work released during the recovery process in partially-constrained recovery experiments was calculated. In this case, samples were unloaded to a value of stress $\sigma_{\text {const }}$ after cooling down. The temperature was increased to $T_{\text {recovery, holding constant }}$ $\sigma_{\text {const }}$ (path 4c) while the strain recovered under constraining stress $\varepsilon_{\mathrm{u}^{\prime}}-\varepsilon_{\mathrm{p}^{\prime}}$ was measured. The work output per volume unit $\left[\mathrm{kJ} / \mathrm{m}^{3}\right]$ was calculated as follows from Equation (4):

$W_{\mathrm{a}}\left[\frac{\mathrm{kJ}}{\mathrm{m}^{3}}\right]=\sigma_{\text {const }} \cdot\left(\varepsilon_{\mathrm{u}^{\prime}}-\varepsilon_{\mathrm{p}^{\prime}}\right)$

The work output is zero when no constraining stress is applied and for fully constrained conditions. Therefore, a maximum in $W_{\mathrm{a}}$ is always present varying $\sigma_{\text {const }}[26]$. Partially-constrained recovery experiments were carried out, maintaining a 20,40 , and $60 \%$ of $\sigma_{\max }\left(\sigma_{\max }=0.75 \cdot \sigma_{\text {break }}\right)$ applied during the temperature ramp.

\section{Results}

\subsection{Curing process}

The effect of the $50 \%$ of BAGA (N50 formulation) and $50 \%$ of ISO (50N formulation) on the curing process was studied in order to ensure that the new components did not affect the dual curing kinetics. Rheological properties evolution during the curing process was also monitored to confirm that the presence of $50 \%$ of BAGA did not move gelation to the second curing stage. Since gelation is a frequencyindependent phenomenon, the gel point was determined as the crossover point of the tan $\delta$ at three different frequencies [24]. These analyses were limited to the formulation with the highest amount of BAGA and ISO. We assumed that the most significant effects would be visible in these cases. In consequence, if no effect was detected, it was assumed that lower percentages would clearly not affect the curing.

Figure 3 shows the evolution of $\tan \delta$ during the first curing stage at $40^{\circ} \mathrm{C}$. The crossover of the $\tan \delta$ curves at different frequencies fall within the first $120 \mathrm{~min}$ of the process, proving that gelation will occur during the first curing stage with the curing procedure established $\left(40{ }^{\circ} \mathrm{C}\right.$ for 2 hours).

The curing kinetics were also analyzed with a dynamic DSC scan to evaluate the effect of the new 


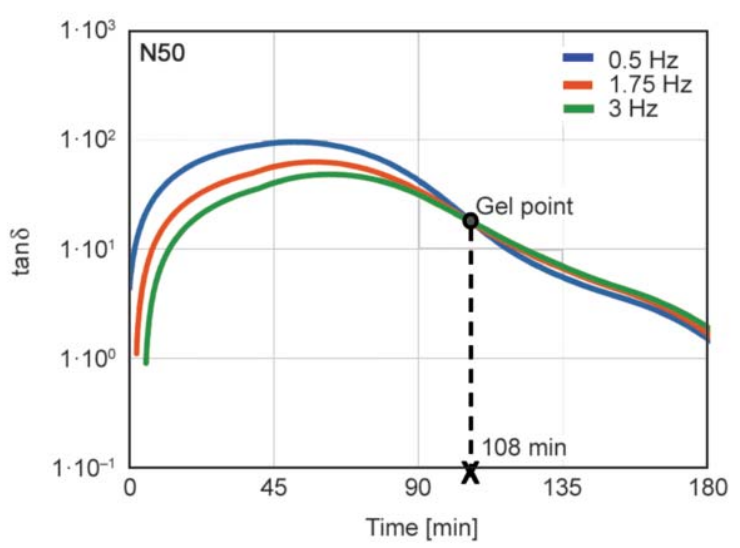

Figure 3. Evolution of $\tan \delta$ with time obtained from the rheological analysis of $\mathrm{N} 50$ during the $1^{\text {st }}$ curing stage at $40^{\circ} \mathrm{C}$.

components on the dual kinetic. The curing kinetics of a dual-curing system were fully characterized in previous publications $[23,24]$ using TCDDA and DGEBA, so the aim of the present analysis is to confirm that no significant changes in the curing time are produced in the first curing step by the addition of BAGA.

First of all, the effect of BAGA on the kinetics of the thiol-acrylate reaction was evaluated comparing the dynamic curing of pure thiol-acrylate samples prepared with TCDDA and TCDDA mixed with BAGA (50:50). Figure 4 a shows no significant changes in the curing kinetics associated with the presence of BAGA. The disappearance of the shoulder visible for NN sample ( $0 \%$ of both BAGA and ISO) only produces a minor change in the shape of the long TCDDA-S4 reaction tale, with no practical effect on the isothermal curing time. The curing behavior of dual formulations with, alternatively, $50 \%$ of BAGA (N50) and $50 \%$ of ISO $(50 \mathrm{~N})$ was compared with the $\mathrm{NN}$ formulation curing behavior (Figure $4 \mathrm{~b}$ ). The first curing reaction, the thiol-acrylate Michael addition, seems to be not affected, while some differences are visible for the second curing reaction, the thiol-epoxy addition. In particular, the separation between the reactions is not clearly affected, even if a slight shift in the curing process is visible. The long reaction tale characteristic of the reaction between TCDDA and $\mathrm{S} 4$ is the reason of the slight overlapping between the two reactions involved. Although this system seems to be no perfectly sequential, in previous works [23, 24], we demonstrated that a strong decrease in the overlapping region is achieved by controlling the first stage curing temperature, obtaining an intermediate material whose properties are quite stable for a significant amount of time at room temperature.

\subsection{Thermomechanical properties}

First, the effect of the addition of ISO and BAGA on thermomechanical properties was investigated separately. Data collected, adding an increasing percentage of ISO are summarized in Table 2. The addition of a different percentage of ISO (Figure 5a) results in a slight increase of the $T_{\mathrm{g}}$ without any improvements in terms of FWHM. Introducing ISO in the

Table 2. Summary of thermomechanical properties of the materials obtained by adding ISO.

\begin{tabular}{|l|c|c|c|c|c|c|}
\hline Formulation & $\begin{array}{c}\boldsymbol{E}_{\mathbf{g}}^{\prime} \mathbf{a} \\
{[\mathbf{M P a}]}\end{array}$ & $\begin{array}{c}\boldsymbol{E}_{\mathbf{r}}^{\prime \mathbf{b}} \\
{[\mathbf{M P a}]}\end{array}$ & $\begin{array}{c}\boldsymbol{T}_{\mathbf{g}} \\
{\left[{ }^{\circ} \mathbf{C}\right]}\end{array}$ & $\begin{array}{c}\boldsymbol{T}_{\mathbf{g}}^{\mathbf{E}^{\prime} \mathbf{c}} \\
{\left[{ }^{\circ} \mathbf{C}\right]}\end{array}$ & $\begin{array}{c}\mathbf{F W H M} \\
{\left[{ }^{\circ} \mathbf{C}\right]}\end{array}$ & $\begin{array}{c}\boldsymbol{E}^{\mathbf{d}} \\
{[\mathbf{M P a}]}\end{array}$ \\
\hline $\mathrm{NN}$ & 3190 & 5.2 & 41.1 & 26 & 14 & 111 \\
\hline $10 \mathrm{~N}$ & 2726 & 12.4 & 42.8 & 29 & 11 & 304 \\
\hline $20 \mathrm{~N}$ & 2848 & 14.1 & 43.3 & 24 & 13 & 347 \\
\hline $50 \mathrm{~N}$ & 3199 & 16.7 & 46.5 & 27 & 16 & 458 \\
\hline
\end{tabular}

${ }^{\mathrm{a} C a l c u l a t e d}$ at $10^{\circ} \mathrm{C}$;

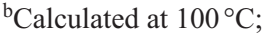

'Onset temperature of the relaxation process;

${ }^{d}$ calculated by Equation (1) at $25^{\circ} \mathrm{C}$
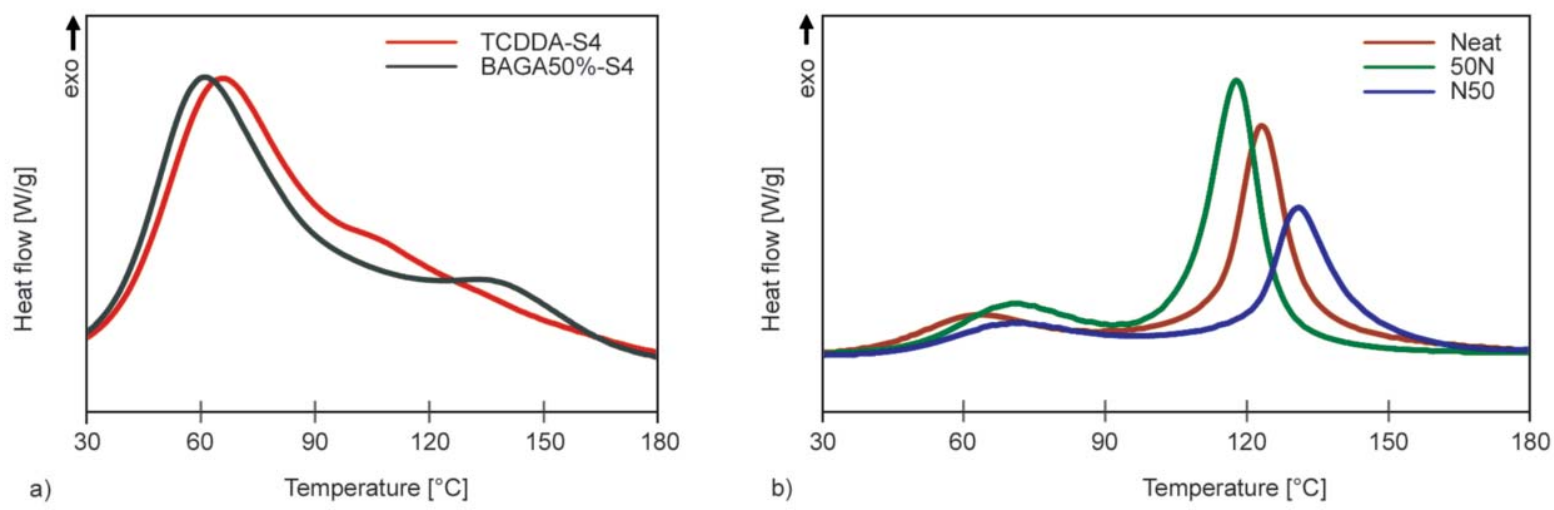

Figure 4. (a) DSC dynamic curing scan of pure thiol-acrylate formulations; (b) DSC dynamic curing scans of 50N and N50 formulations compared with the neat formulation. 

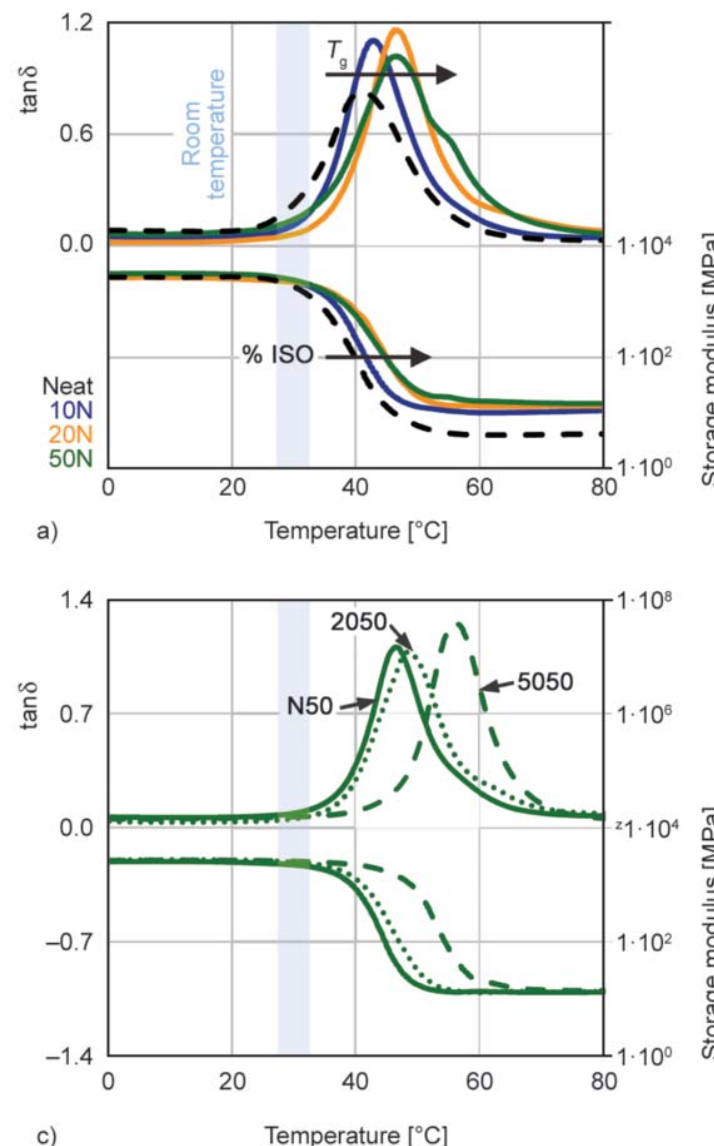
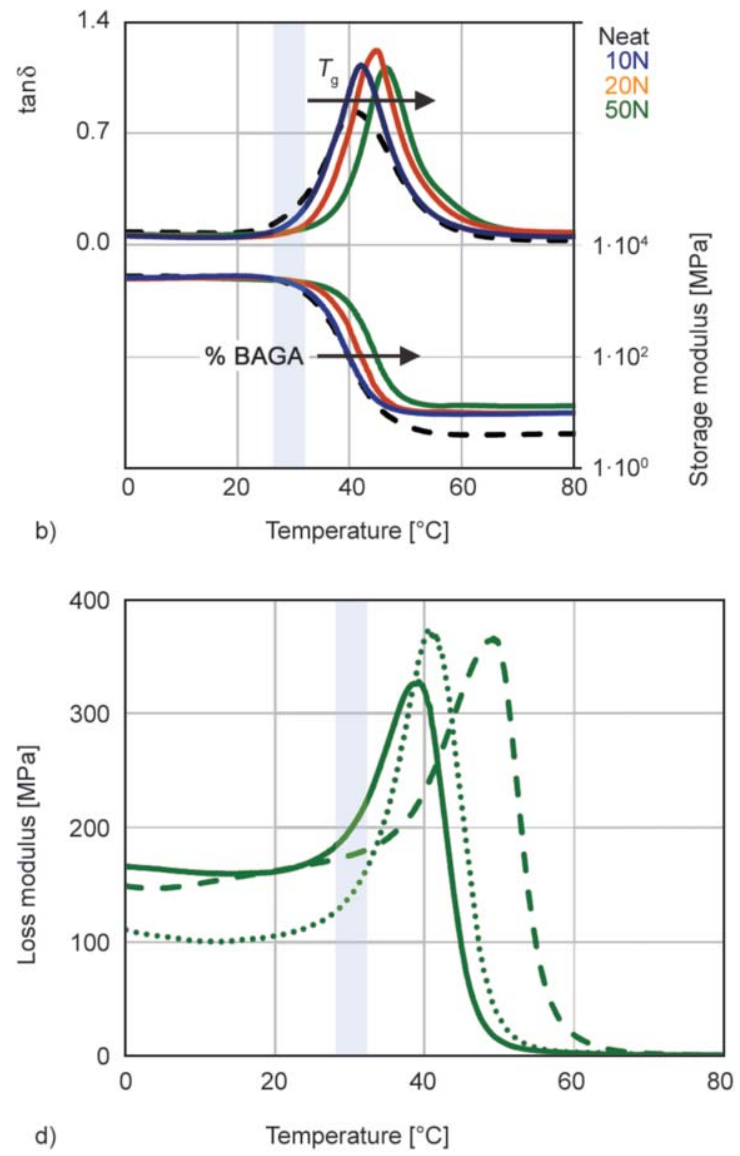

Figure 5. Evolution of storage modulus and tan $\delta$ along temperature during dynamic mechanical analysis: effect of the addition of (a) ISO, (b) BAGA and (c) both compounds. (d) Loss modulus evolution with temperature for N50, 2050 and 5050 formulations.

mixture implies the introduction of new crosslinking points in the final network, which leads to a more restricted molecular mobility, thus increasing $T_{\mathrm{g}}$. Transitions remain as wide as the one of the neat samples, with a further broadening in the case of $50 \mathrm{~N}$ caused by the appearance of a shoulder, as already reported by Belmonte et al. [16]. The increase in crosslinking density is confirmed by the increase in $E_{\mathrm{r}}^{\prime}$, which is considered to be roughly proportional to the crosslinking density. The values of the flexural modulus $E$ at $25^{\circ} \mathrm{C}$ are quite low in comparison with the values of the storage modulus at $10^{\circ} \mathrm{C} E_{\mathrm{g}}^{\prime}$ because network relaxation is already active at $25^{\circ} \mathrm{C}$, as deduced from the relaxation curves in Figure 5a. However, it slightly improves with increasing ISO because of the shifting of the network relaxation to higher temperatures.

A similar effect on the glass transition temperature has been detected, adding different proportions of BAGA to the formulation (Figure $5 \mathrm{~b}$ and Table 3 ). Some authors have described a positive effect of the presence of hydroxyl groups on $T_{\mathrm{g}}$ due to the presence of hydrogen-bonds [19] interaction, which
Table 3. Summary of thermomechanical properties of the materials obtained adding BAGA.

\begin{tabular}{|l|c|c|c|c|c|c|}
\hline Formulation & $\begin{array}{c}\boldsymbol{E}_{\mathbf{g}}^{\prime} \\
{[\mathbf{M P a}]}\end{array}$ & $\begin{array}{c}\boldsymbol{E}_{\mathbf{r}}^{\prime} \\
{[\mathbf{M P a}]}\end{array}$ & $\begin{array}{c}\boldsymbol{T}_{\mathbf{g}} \\
{\left[{ }^{\circ} \mathbf{C}\right]}\end{array}$ & $\begin{array}{c}\boldsymbol{T}_{\mathbf{g}}^{\mathbf{E}^{\prime}} \\
{\left[{ }^{\circ} \mathbf{C}\right]}\end{array}$ & $\begin{array}{c}\mathbf{F W H M} \\
{\left[{ }^{\circ} \mathbf{C}\right]}\end{array}$ & $\begin{array}{c}\boldsymbol{E} \\
{[\mathbf{M P a}]}\end{array}$ \\
\hline NN & 3190 & 5.2 & 41 & 26 & 14 & 111 \\
\hline N10 & 2810 & 10.9 & 42 & 27 & 11 & 207 \\
\hline N30 & 2629 & 10.7 & 44 & 30 & 9 & 414 \\
\hline N50 & 2576 & 14.7 & 47 & 33 & 9 & 892 \\
\hline
\end{tabular}

affects the network mobility delaying the glass transition. However, Xie and Rousseau [27] reported a decrease in $T_{\mathrm{g}}$ in a series of epoxy-amine based SMPs in spite of the increase of crosslinking density and, consequently, hydroxyl groups. It is acknowledged that hydroxyl groups mainly have an influence on the cohesive properties of the material and on the glassy modulus [28]. In contrast, the glass transition temperature, which is more related to network mobility, is generally connected with the rigidity of the network strands and the crosslinking density [28]. The effect observed in this work may be analogous to the one described by Xie and Rousseau [27]. The 
addition of BAGA reduces the crosslinking density of the material due to the larger size of the BAGA monomer in comparison with TCDDA, but the inherent rigidity of the bisphenol A structure in the BAGA monomer makes up for it and even produces an increase in $T_{\mathrm{g}}$. Moreover, the FWHM is significantly reduced, adding a percentage of BAGA to the formulation leading to more homogeneous network structure with sharp transitions that better fit the shape-memory requirements. Consequently, the increase in $T_{\mathrm{g}}$, along with the decrease in FWHM explains the higher value of $E$ at $T_{\text {room }}$ (Table 3).

In Figure $5 \mathrm{c}$ and Table 4 are shown the results obtained for the 2050 (20\% of ISO and $50 \%$ of BAGA) and 5050 ( $50 \%$ of ISO and $50 \%$ of BAGA) formulations, which combine both components, in comparison with the N50 formulation. A slight increase in $T_{\mathrm{g}}$ is visible using $20 \%$ of ISO, while a significant increase is detected using $50 \%$. Moreover, the addition of ISO produces only a discrete increase in FWHM, which remains around $10^{\circ} \mathrm{C}$. The evolution of the loss modulus ( $\left.E^{\prime \prime}\right)$ against temperature for these formulations shows that the $E^{\prime \prime}$ peak is shifted to temperatures higher than $T_{\text {room }}$, thereby increasing the glassy state stability (Figure 5d). Accordingly, we can also appreciate the positive effect of ISO on the flexural modulus (Table 4) caused by the shift of $T_{\mathrm{g}}$ to higher temperatures, as discussed previously.

A significant difference in storage modulus between the glassy and rubbery states is a crucial requirement for shape-memory polymers [29]. In order to have good control of the recovery process, the onset of the relaxation process has to be a bit higher than the room temperature in order to avoid unintended recovery of the shape when samples are stored at $T_{\text {room. }}$. Furthermore, the value of FWHM is important because of its influence on the shape recovery speed.

Considering that all investigated materials meet the requirement in terms of $E_{\mathrm{g}}^{\prime} / E_{\mathrm{r}}^{\prime}$, samples for shapememory characterization were chosen to look at the characteristic parameters of the relaxation process $\left(T_{\mathrm{g}}, T_{\mathrm{g}}^{\mathrm{E}^{\prime}}, \mathrm{FWHM}\right)$. To this end N50, 2050 and 5050 appears to be the best candidates since they present suitable $T_{\mathrm{g}} \mathrm{s}$ for our purpose together with narrow $\tan \delta$ peaks and $T_{\mathrm{g}}^{\mathrm{E}^{\prime}}$ higher than $30^{\circ} \mathrm{C}$. In spite of having a $T_{\mathrm{g}}^{\mathrm{E}^{\prime}}$ lower than $30^{\circ} \mathrm{C}$, we chose to study also the behavior of $20 \mathrm{~N}$ and $50 \mathrm{~N}$ in order to isolate the effect of the ISO percentage in samples that present the advantage of being programmable at room temperature, without any additional heat.
Table 4. Summary of thermomechanical properties obtained, adding both BAGA and ISO.

\begin{tabular}{|l|c|c|c|c|c|c|}
\hline Formulation & $\begin{array}{c}\boldsymbol{E}_{\mathbf{g}}^{\prime} \\
{[\mathbf{M P a}]}\end{array}$ & $\begin{array}{c}\boldsymbol{E}_{\mathbf{r}}^{\prime} \\
{[\mathbf{M P a}]}\end{array}$ & $\begin{array}{c}\boldsymbol{T}_{\mathbf{g}} \\
{\left[{ }^{\circ} \mathbf{C}\right]}\end{array}$ & $\begin{array}{c}\boldsymbol{T}_{\mathbf{g}}^{\mathbf{E}^{\prime}} \\
{\left[{ }^{\circ}{ }^{\circ} \mathbf{C}\right]}\end{array}$ & $\begin{array}{c}\mathbf{F W H M} \\
{\left[{ }^{\circ} \mathbf{C}\right]}\end{array}$ & $\begin{array}{c}\boldsymbol{E} \\
{[\mathbf{M P a}]}\end{array}$ \\
\hline $\mathrm{N} 50$ & 2576 & 14.7 & 47 & 33 & 9 & 892 \\
\hline 2050 & 2739 & 14.7 & 48 & 33 & 11 & 1188 \\
\hline 5050 & 3067 & 16.3 & 56 & 41 & 10 & 1298 \\
\hline
\end{tabular}

\subsection{Shape-memory behavior}

\subsubsection{Mechanical properties}

Tensile test at $T_{\mathrm{g}}^{\mathrm{E}^{\prime}}$ were made to evaluate the limit of these materials during the programming process. The values of stress at break $\left(\sigma_{\mathrm{b}}\right)$ and strain at break $\left(\varepsilon_{\mathrm{b}}\right)$, are of paramount importance in shape-memory performance because they estimate the network capability to store strain for successive recovery. The strain energy density (SED), calculated as the area under the stress-strain diagram, is the energy required for the programming of the material as it is deformed. It should not correspond to the energy stored because of the large dissipation of the energy produced by the network relaxation during deformation at $T_{\mathrm{g}}^{\mathrm{E}^{\prime}}$, but it gives a qualitative idea in comparative terms. In fact, it is observed that $\varepsilon b$ and SED are fairly proportional, given that the network relaxation behavior and relaxed modulus of the different systems are not that different.

Tensile modulus in Table 5 correlates well with the trend found for $E_{\mathrm{r}}^{\prime}$ values since the relaxation time at $T_{\mathrm{g}}^{\mathrm{E}^{\prime}}$ is comparable with the tensile test time-scale.

N50 exhibits a high level of deformation at break and, due to a strain-hardening effect, values of $\sigma_{\text {break }}$ close to the one obtained using the ISO compound $(50 \mathrm{~N}$ and $20 \mathrm{~N})$. Both formulations with ISO show a behavior dictated from their higher level of crosslinking, which leads to the same level of stress but at a lower level of deformation at break. The behavior of the mixtures of both ISO and BAGA (2050 and 5050) seems to be improved in terms of ductility by the presence of BAGA, but the increase in crosslinking density limits the strain-hardening effect

Table 5. Tensile data at $T_{\mathrm{g}}^{\mathrm{E}^{\prime}}$ obtained by DMA.

\begin{tabular}{|l|c|c|c|c|c|}
\hline Formulation & $\begin{array}{c}\boldsymbol{\sigma}_{\text {break }} \\
{[\mathbf{M P a}]}\end{array}$ & $\begin{array}{c}\boldsymbol{\varepsilon}_{\text {break }} \\
{[\%]}\end{array}$ & $\begin{array}{c}\boldsymbol{E}_{\mathbf{t}} \\
{[\mathbf{M P a}]}\end{array}$ & $\begin{array}{c}\mathbf{S E D} \\
{\left[\mathbf{k J} / \mathbf{m}^{\mathbf{3}}\right]}\end{array}$ & $\begin{array}{c}\boldsymbol{T}_{\mathbf{g}}^{\mathrm{E}^{\prime}} \\
{\left[{ }^{\circ} \mathbf{C}\right]}\end{array}$ \\
\hline $\mathrm{N} 50$ & 13.6 & 107.1 & 199 & 7040 & 33.0 \\
\hline $20 \mathrm{~N}$ & 12.5 & 55.2 & 298 & 4842 & 24.0 \\
\hline $50 \mathrm{~N}$ & 13.2 & 35.0 & 357 & 3746 & 26.7 \\
\hline 2050 & 9.3 & 74.5 & 595 & 5351 & 33.2 \\
\hline 5050 & 10.2 & 48.7 & 696 & 4020 & 40.7 \\
\hline
\end{tabular}


causing a decrease in the final strength of 2050 and 5050 .

The high deformation at break reached with N50 results also in the highest SED. If one compares the values obtained for 2050 and 5050 with the one obtained for $20 \mathrm{~N}$ and $50 \mathrm{~N}$, it can be clearly observed the increase in ductility caused by the presence of BAGA, thereby leading to higher values of SED. On the other hand, the presence of ISO reduces ductility and, in consequence, SED. There is a close relation between SED and the work generation during partially-constrained recovery, as it will be demonstrated in the following section. We would expect that the work output in materials with of $50 \%$ of BAGA is higher due to their capability to store higher energy during deformation.

\subsubsection{Free recovery tests}

Taking into consideration the relaxation curves obtained from DMA analysis (section 3.2), the fixation temperature $T_{\text {low }}$ was set to $10^{\circ} \mathrm{C}$. This temperature is located within the $E^{\prime}$ plateau in the glassy region and far enough from the modulus drop for all the samples tested. Results obtained in free recovery conditions are shown in Figure 6. Fixation rates close to $100 \%$ were obtained for all analyzed samples meaning that at $10^{\circ} \mathrm{C}$ all samples have low network mobility, regardless of the crosslinking density. Excellent results were also obtained in terms of Recovery ratio, which is about $95-97 \%$. The lowest $R_{\mathrm{r}}$ value was found in N50 sample (100\% of DGEBA and $50 \%$ of BAGA) due to the damage produced by the excessive programming strain [17], which was selected, taking into account the large strain at break related with the strain-hardening phenomenon mentioned before. Plasticization related to this effect, caused by the production of irreversible damage to the network structure, leads to the presence of a higher portion of unrecoverable deformation after the programming step for N50. As shown in Figure 6b, the onset of the recovery process has a good correlation with the $T_{\mathrm{g}}$ of the samples. Besides the optimal results in terms of $R_{\mathrm{r}}$ and $R_{\mathrm{f}}$ obtained, samples of N50, $20 \mathrm{~N}$ and $50 \mathrm{~N}$ start to recover too close to $T_{\text {room }}$ undermining their application. On the contrary, the higher $T_{\mathrm{g}}$ of 2050 and 5050 shifts the recovery process to higher temperatures, therefore, avoiding premature recovery. Therefore, it can be concluded that we have at our disposal a high-quality SME activated at different temperatures.

\subsubsection{Fully-constrained recovery tests}

The recovery stress generation was measured with a fully constrained shape-recovery test at $8 \mathrm{MPa}$, a stress value within the failure limits of each formulation. Figure 9a shows the recovery stress generation of sample programmed at $8 \mathrm{MPa}$. During the recovery process, the recovery stress progressively increases with temperature until a maximum is reached at $T_{\text {recovery }}$ marked in Figure 7a. In general, two competitive thermomechanical processes are involved in the recovery stress generation: a constrained thermal expansion that generates a compression plateau at lower temperature and the shape-memory effect, which produces a shift towards positive stress values when activated at higher temperature $[26,30]$. In this case, no compression plateau is visible because of the relatively low transition temperatures of these materials. As shown in Figure 7b, 2050 and 5050 generate the highest values of recovery stress while $20 \mathrm{~N}$ and $50 \mathrm{~N}$ exhibit the lowest ones. Some studies in the literature have shown that more crosslinked
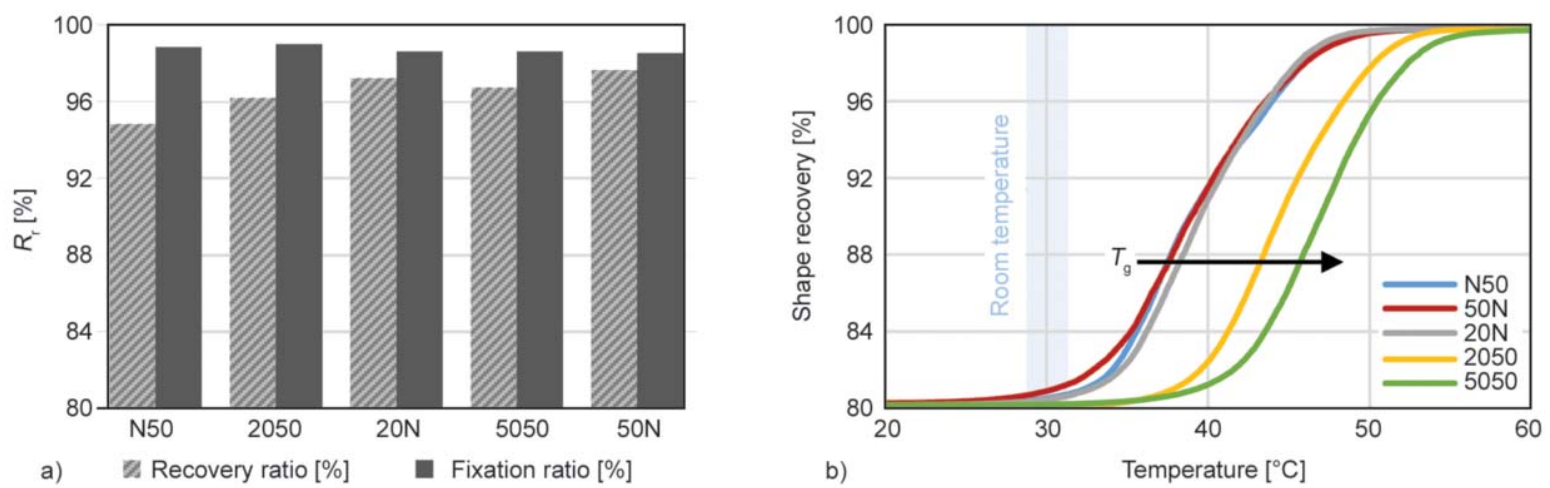

Figure 6. (a) Average values of recovery $\left(R_{\mathrm{r}}\right)$ and fixation $\left(R_{\mathrm{f}}\right)$ rate values from three consecutive free-recovery SMCs; (b) Shape-recovery [\%] along temperature during the recovery step of the third cycle. 

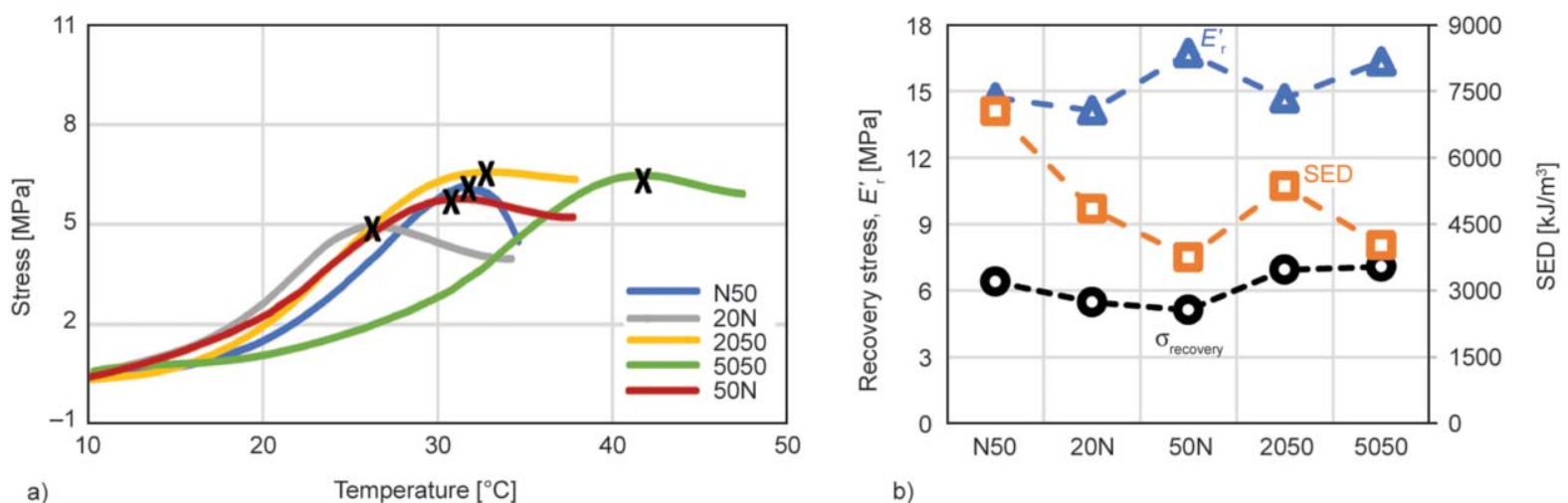

b)

Figure 7. (a) Recovery stress generation as function of temperature during a recovery stage of samples programmed at $8 \mathrm{MPa}$ of maximum stress; (b) Values of the maximum stress generated during the recovery stage (0) compared with the values of strain energy density $(\square)$ and storage modulus in the rubbery state $(\Delta)$.

networks exercise higher driving recovery forces making the crosslinking density the key factor in recovery stress generation $[18,30]$. In our case, there seems to be some correlation between SED or, as discussed above, the deformability of the material, and the maximum recovered stress. Still, the effect is complex, given that it might also depend on the apparent crosslinking density or relaxed modulus and, especially, the underlying thermal expansion during network relaxation, which in the current experimental setup would have an opposite effect.

To the best of our knowledge, the values obtained are positioned between the highest values found in the literature. Arrieta et al. [31] reported recovery stress of around $6 \mathrm{MPa}$ in an acrylic based shapememory polymer pre-strained to $55 \%$. Ortega et al. [32] reported recovery stress of almost $4 \mathrm{MPa}$ in (meth)acrylated based shape-memory polymers. Hashmi et al. [33] enhanced the recovery stress of polyurethanes to $6.95 \mathrm{MPa}$ by means of MWCNTs. Although Santiago et al. [26] reported that hyperbranched amine-epoxy SMPs reached values of

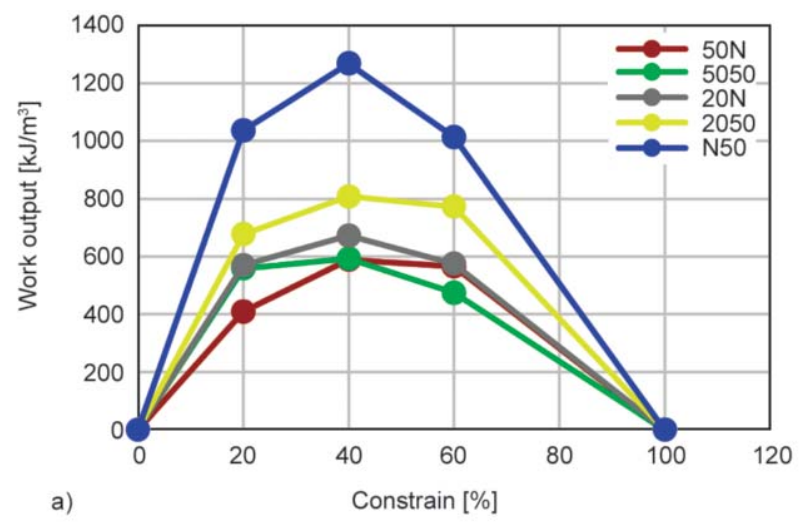

$7 \mathrm{MPa}$ of stress generated, the stress used to program the samples was $10 \mathrm{MPa}$. Li et al. [35] obtained higher values of around $17 \mathrm{MPa}$ using UV-cured thermosets [34] and around $14 \mathrm{MPa}$ after recycling the same thermosets. In the former cases, samples were programmed in compression, reaching values of deformation that cannot be easily obtained in tension.

\subsubsection{Partially-constrained recovery tests}

The level of work output given by the materials during partially-constrained recovery tests was measured under a constrain percentage of 20,40 and $60 \%$ of $\sigma_{\max }$, and the results are presented in Figure 8. The best results were obtained with N50, which was able to generate a significantly higher work under any constraining level (Figure 8a), reaching a maximum value of about $1300 \mathrm{~kJ} / \mathrm{m}^{3}$ when a $40 \%$ of the omax was maintained during the recovery. Work output, calculated by Equation (4), strongly depends on the deformation obtained after the programming step $\varepsilon_{\mathrm{u}^{\prime}}$ which is directly related to $\varepsilon_{\text {break }}$ of the material and the SED used during programming. As shown in a

Figure 8. (a) Variation of Work output with the constraining percentage; (b) values of Work output at 20, 40 and $60 \%$ of constrain compared with strain energy density (SED).

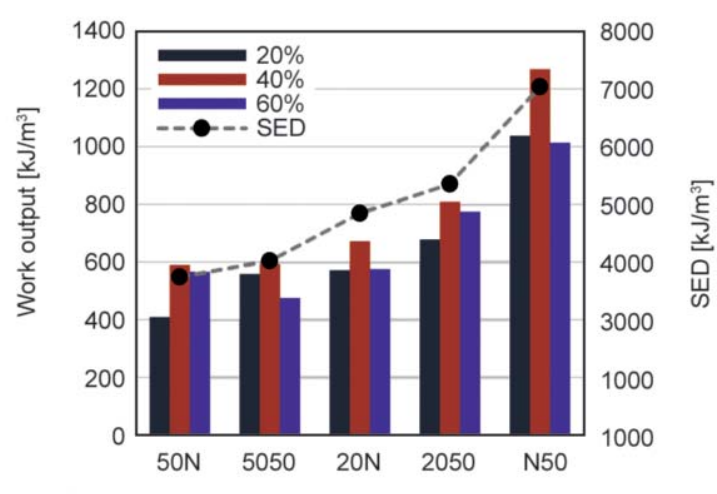

b) 
previous section, N50 exhibit the highest value of strain at break and, consequently, the highest value of SED, which constitutes the main reasons behind its ability to produce a higher work output. Figure $8 \mathrm{~b}$ presents the work output values obtained for all the percentages of constrain and compares them with the SED, showing a good correlation. Materials with more crosslinked networks have a lower work output during recovery due to their lower ductility at $T_{\mathrm{g}}^{\mathrm{E}^{\prime}}$. This indicates that deformability plays a fundamental role in work output rather than croslinking density.

However, the values obtained are considerably higher than values reported in the literature: Santiago et al. [26] obtained a maximum value of $750 \mathrm{~kJ} / \mathrm{m}^{3}$ with hyperbranched epoxy polymers Lakhera et al. [29] reached values of around $300 \mathrm{~kJ} / \mathrm{m}^{3}$ in acrylate-based thermosets programmed in compression; Rapp and Baier [30] reported a maximum of $280 \mathrm{~kJ} / \mathrm{m}^{3}$ in polystyrene-based Veriflex ${ }^{\circledR}[30]$. These thiol-acrylateepoxy thermosets showed are able to perform remarkable work output from 400 to almost $1300 \mathrm{~kJ} / \mathrm{m}^{3}$, confirming the high potentiality of these materials.

The shape-recovery process was also analysed in terms of shape recovery rate. The instantaneous shaperecovery rate $S R_{\text {rate }}(t)$ was calculated using Equation (5):

$\operatorname{SR}_{\mathrm{rate}}(t)=\frac{\mathrm{d} R_{\mathrm{r}}}{\mathrm{d} t}$

Instead, when fully-constrained conditions are applied, the stress generation rate $S G_{\text {rate }}(t)$ was calculated from the stress recovery curve by means of Equation (6):

$S G_{\text {rate }}(t)=\frac{\mathrm{d} \sigma_{\text {recovery }}}{\mathrm{d} t}$

The temperature at which the maximum recovery rate is found ( $\left.T_{\text {peak }}\right)$, and the duration of the process as the width of the curve at half-height $\left(\Delta T_{\text {peak }}\right)$ were determined. The velocity of the recovery procees $\left(V_{\mathrm{r}}\right)$ was calculated as the shape-recovery rate between 15 and $85 \%$ of $R_{\mathrm{r}}$ from Equation (7):

$V_{\mathrm{r}}=\frac{\Delta R_{\mathrm{r}, 15 \%-85 \%}}{\Delta T_{15 \%-85 \%}} \cdot \frac{\mathrm{d} T}{\mathrm{~d} t}$

Results collected in Table 6 shows that formulations with a higher crosslinking degree present higher values of $V_{\mathrm{r}}$ and a narrower shape-recovery rate peak (lower $\Delta T_{\text {peak }}$ ). As reported by Belmonte et al. [36], the width of the relaxation process deduced from FWHM values is closely related to the shape-recovery rate in glassy materials, which should exhibit a faster recovery when narrower transitions are obtained. In our case, results obtained for the recovery speed for N50 do not correlate with the results obtained for FWHM in Table 3. The explanation can be found in the shape of the $S R_{\text {rate }}$ curves (Figure 9a). As shown in Figure 9a inset, a shoulder in the N50 recovery rate curve is present. This indicates that the recovery process is slowed down due to damages caused to the network at the high level of strain at which the material is programmed. Materials obtained only with the ISO have a slower $V_{\mathrm{r}}$ than 2050 and 5050 as one would expect from their high FWHM values. As it can be seen for any material, values of $T_{\text {peak }}$ are slightly below the $T_{\mathrm{g}}$ and vary materials $T_{\mathrm{g}}$ (Tables 2-4).

The effect of the $\%$ of constraint on the evolution of the recovery rate along time during a partially-constrained recovery test was studied, as shown in Figure $9 \mathrm{~b}$ for $\mathrm{N} 50$. The recovery process necessitates a slightly higher temperature to starts when constraining stress is applied, but the effect is very small. This is confirmed by the values of $T_{\text {peak, }}$, which are slightly shifted to higher values with respect to the unconstrained recovery. It is noteworthy that the values of $T_{\text {peak }}$ almost match the loss modulus peak temperature

Table 6. Parameters obtained from the shape-memory analysis (unconstrained, fully-constrained, partially constrained) of the different materials under investigation.

\begin{tabular}{|c|c|c|c|c|c|c|c|c|c|c|}
\hline & \multicolumn{3}{|c|}{ Fully-constrained } & \multicolumn{3}{|c|}{ Partially-constrained $(40 \%)$} & \multicolumn{4}{|c|}{ Unconstrained } \\
\hline & $\begin{array}{c}\Delta T_{\text {peak }} \\
{\left[{ }^{\circ} \mathrm{C}\right]}\end{array}$ & $\begin{array}{l}T_{\text {peak }} \\
{\left[{ }^{\circ} \mathrm{C}\right]}\end{array}$ & $\begin{array}{c}\sigma_{\text {recovery }} \\
{[\mathrm{MPa}]}\end{array}$ & $\begin{array}{c}\Delta T_{\text {peak }} \\
{\left[{ }^{\circ} \mathrm{C}\right]}\end{array}$ & $\begin{array}{l}T_{\text {peak }} \\
{\left[{ }^{\circ} \mathbf{C}\right]}\end{array}$ & $\begin{array}{c}W_{\mathrm{a}} \\
{\left[\mathrm{kJ} / \mathrm{m}^{3}\right]}\end{array}$ & $\begin{array}{c}\Delta T_{\text {peak }} \\
{\left[{ }^{\circ} \mathbf{C}\right]}\end{array}$ & $\begin{array}{l}T_{\text {peak }} \\
{\left[{ }^{\circ} \mathrm{C}\right]}\end{array}$ & $\begin{array}{c}V_{\mathrm{r}} \\
{[\% / \min ]}\end{array}$ & $\begin{array}{c}R_{\mathrm{r}} \\
{[\%]}\end{array}$ \\
\hline N50 & 11 & 32 & 6.4 & 12 & 42 & 1268 & 12 & 39 & 21.0 & 95.21 \\
\hline $20 \mathrm{~N}$ & 8 & 26 & 5.5 & 11 & 42 & 672 & 11 & 40 & 24.2 & 97.24 \\
\hline $50 \mathrm{~N}$ & 7 & 27 & 5.1 & 11 & 44 & 590 & 11 & 40 & 21.5 & 97.65 \\
\hline 2050 & 12 & 33 & 6.9 & 10 & 49 & 809 & 10 & 44 & 25.4 & 96.20 \\
\hline 5050 & 14 & 42 & 7.1 & 10 & 45 & 593 & 9 & 49 & 26.2 & 96.74 \\
\hline
\end{tabular}



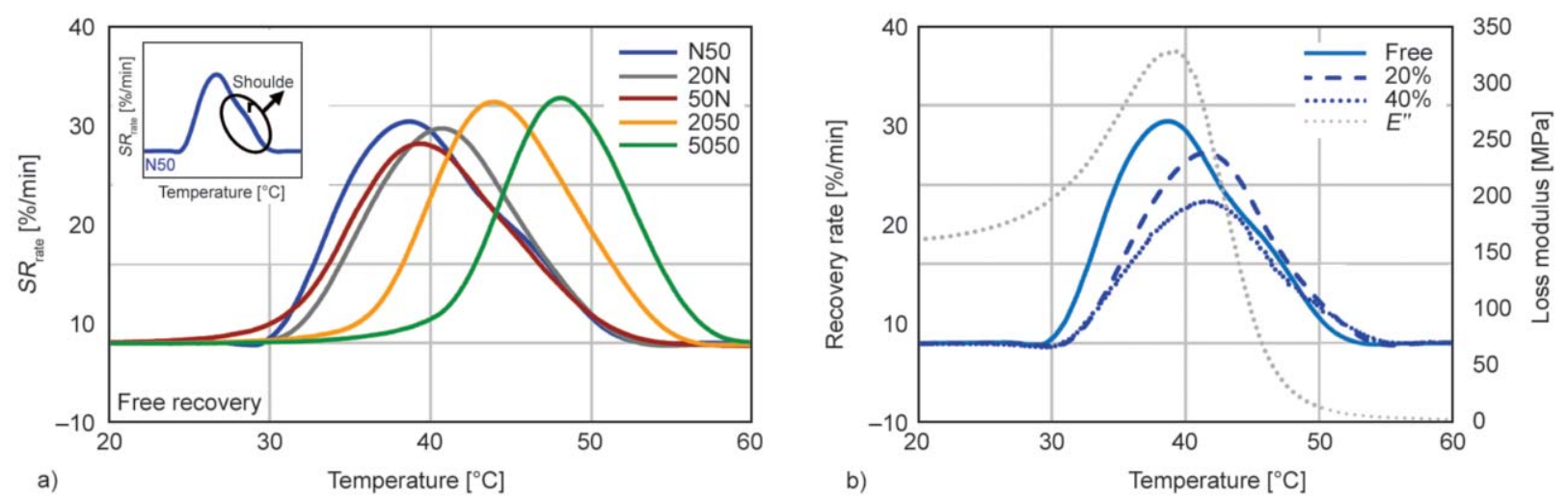

Figure 9. (a) Recovery rate variation with temperature during the free-recovery process; (b) effect of the constraining percentage on the recovery rate curve of N50 samples.

which is the most accredited criterion to determine the $T_{\mathrm{g}}$ from DMA analysis. In contrast, $T_{\text {peak }}$ in fullyconstrained recovery experiment is significantly reduced compared to the other recovery conditions. The stress generation, in contrast with the recovery of the shape in free and partially-constrained experiments, starts earlier, and $T_{\text {peak }}$ turns out to be close to $T_{\mathrm{g}}^{\mathrm{E}^{\prime}}$. This can be rationalized in terms of the kinetics of network relaxation. It is well known that creep phenomena are retarded with respect to stress relaxation due to the nature of viscoelastic relaxation processes. Consequently, free or partially constrained shape recovery processes should always be delayed with respect to stress build-up in fully constrained processes.

\section{Conclusions}

In this work, we modified the network structure of thiol-epoxy-acrylate thermosets introducing different percentages of ISO and BAGA in order to obtain final properties suitable for soft actuation.

DSC dynamic analysis revealed no significant effects on the dual-curing kinetics, curing reactions maintain an acceptable separation. The evolution of the rheological properties during the first curing stage at $40^{\circ} \mathrm{C}$ confirmed that gelation still occurs during the first curing step, even if $50 \%$ of BAGA was used.

The thermomechanical properties of the final materials were successfully enhanced by the modification of the network structure introduced by the new components. Increasing the percentage of ISO led to an increase in crosslinking density, which is reflected by flexural modulus and glass transition temperatures increase. BAGA has similar effects in terms of $T_{\mathrm{g}}$ together with a strong reduction in FWHM parameter. The relaxation process is steeper and is moved to higher temperatures causing a significant enhancement of material stiffness at room temperature. Materials obtained with the combination of 20 and $50 \%$ of ISO with the $50 \%$ results to be the best one thanks to a simultaneous enhance in terms of $T_{\mathrm{g}}$ and network rigidity.

Free-recovery experiments showed an efficient recovery process for all studied materials. The fullyconstrained recovery experiments showed an excellent capability of these materials to generate stress (up to $7 \mathrm{MPa}$ ) on heating above $T_{\mathrm{g}}$ due to the combination of high ductility and more crosslinked structure. Finally, partially-constrained recovery experiments demonstrated the capability of these materials to produce a high work output (up to $1300 \mathrm{~kJ} / \mathrm{m}^{3}$ ) during recovery thanks to the high energy stored during programming process.

In general, N50, 2050, and 5050 showed excellent shape-memory performances in all recovery scenarios proving they could be suitable to be used as actuator in mechanical demanding applications.

\section{Acknowledgements}

The authors would like to thank MCIU (Ministerio de Ciencia, Innovación y Universidades) and FEDER (Fondo Europeo de Desarrollo Regional) (MAT2017-82849-C2-1-R and MAT2017-82849-C2-2-R) and Generalitat de Catalunya (2017-SGR-77 and Serra Húnter programme) for the financial support.

\section{References}

[1] Lendlein A., Kelch S.: Shape-memory polymers. Angewandte Chemie International Edition, 41, 2034-2057 (2002).

https://doi.org/10.1002/1521-3773(20020617)41:12\%3C2034 $\because$ AID-ANIE2034\%3E3.0.CO;2-M 
[2] Liu Y., Du H., Liu L., Leng J.: Shape memory polymers and their composites in aerospace applications: A review. Smart Materials and Structures, 23, 023001/1023001/23 (2014).

https://doi.org/10.1088/0964-1726/23/2/023001

[3] Fang L., Fang T., Liu X., Chen S., Lu C., Xu Z.: Nearinfrared light triggered soft actuators in aqueous media prepared from shape-memory polymer composites. Macromolecular Materials and Engineering, 301, 11111120 (2016).

https://doi.org/10.1002/mame.201600139

[4] Behl M., Kratz K., Noechel U., Sauter T., Lendlein A.: Temperature-memory polymer actuators. Proceedings of the National Academy of Sciences of the United States of America, 110, 12555-12559 (2013).

https://doi.org/10.1073/pnas.1301895110

[5] Reeder J., Kaltenbrunner M., Ware T., Arreaga-Salas D., Avendano-Bolivar A., Yokota T., Inoue Y., Sekino M., Voit W., Sekitani T., Someya T.: Mechanically adaptive organic transistors for implantable electronics. Advanced Materials, 26, 4967-4973 (2014).

https://doi.org/10.1002/adma.201400420

[6] Chen S., Yang S., Li Z., Xu S., Yuan H., Chen S., Ge Z.: Electroactive two-way shape memory polymer laminates. Polymer Composites, 36, 439-444 (2015). https://doi.org/10.1002/pc.22958

[7] Yang D., Huang W., He X., Xie M.: Electromagnetic activation of a shape memory copolymer matrix incorporating ferromagnetic nanoparticles. Polymer International, 61, 38-42 (2012).

https://doi.org/10.1002/pi.3188

[8] Lendlein A., Jiang H., Jünger O., Langer R.: Light-induced shape-memory polymers. Nature, 434, 879-882 (2005). https://doi.org/10.1038/nature03496

[9] Santiago D., Fabregat-Sanjuan A., Ferrando F., De la Flor S.: Hyperbranched-modified epoxy thermosets: Enhancement of thermomechanical and shape-memory performances. Journal of Applied Polymer Science, 134, 44623/1-44623/11 (2017).

https://doi.org/10.1002/app.44623

[10] Berg G. J., McBride M. K., Wang C., Bowman C. N.: New directions in the chemistry of shape memory polymers. Polymer, 55, 5849-5872 (2014).

https://doi.org/10.1016/j.polymer.2014.07.052

[11] Parker S., Reit R., Abitz H., Ellson G., Yang K., Lund B., Voit W. E.: High- $T_{\mathrm{g}}$ thiol-click thermoset networks via the thiol-maleimide michael addition. Macromolecular Rapid Communications, 37, 1027-1032 (2016). https://doi.org/10.1002/marc.201600033

[12] Feldkamp D. M., Rousseau I. A.: Effect of chemical composition on the deformability of shape-memory epoxies. Macromolecular Materials and Engineering, 296, 1128-1141 (2011).

https://doi.org/10.1002/mame.201100066
[13] Leonardi A. B., Fasce L. A., Zucchi I. A., Hoppe C. E., Soulé E. R., Pérez C. J., Williams R. J. J.: Shape memory epoxies based on networks with chemical and physical crosslinks. European Polymer Journal, 47, 362-369 (2011).

https://doi.org/10.1016/j.eurpolymj.2010.12.009

[14] Yakacki C. M., Willis S., Luders C., Gall K.: Deformation limits in shape-memory polymers. Advanced Engineering Materials, 10, 112-119 (2008).

https://doi.org/10.1002/adem.200700184

[15] Feldkamp D. M., Rousseau I. A.: Effect of the deformation temperature on the shape-memory behavior of epoxy networks. Macromolecular Materials and Engineering, 295, 726-734 (2010). https://doi.org/10.1002/mame.201000035

[16] Belmonte A., Guzmán D., Fernández-Francos X., De la Flor S.: Effect of the network structure and programming temperature on the shape-memory response of thiol-epoxy 'click' systems. Polymers, 7, 2146-2164 (2015).

https://doi.org/10.3390/polym7101505

[17] Belmonte A., Fernández-Francos X., De la Flor S.: New understanding of the shape-memory response in thiolepoxy click systems: Towards controlling the recovery process. Journal of Materials Science, 52, 1625-1638 (2017). https://doi.org/10.1007/s10853-016-0456-9

[18] Yakacki C. M., Shandas R., Safranski D., Ortega A. M., Sassaman K., Gall K.: Strong, tailored, biocompatible shape-memory polymer networks. Advanced Functional Materials, 18, 2428-2435 (2008).

https://doi.org/10.1002/adfm.200701049

[19] Antony G. J. M., Aruna S. T., Samikkannu R., Jarali C. S.: Effect of cross-linking agent on the thermo-mechanical properties of acrylate shape memory polymer network. in 'Frontiers in materials processing, applications, research and technology' (eds.: Muruganant M., Chirazi A., Raj B.) Springer, Singapore, 359-364 (2018). https://doi.org/10.1007/978-981-10-4819-7 31

[20] Santiago D., De la Flor S., Ferrando F., Ramis X., Sangermano M.: Thermomechanical properties and shape-memory behavior of Bisphenol A diacrylatebased shape-memory polymers. Macromolecular Chemistry and Physics, 217, 39-50 (2016). https://doi.org/10.1002/macp.201500261

[21] Dhulst E. A., Heath W. H., Torkelson J. M.: Hybrid thiol-acrylate-epoxy polymer networks: Comparison of one-pot synthesis with sequential reactions and shape memory properties. Polymers, 96, 198-204 (2016). https://doi.org/10.1016/j.polymer.2016.04.032

[22] Ramis X., Fernández-Francos X., De la Flor S., Serra Á.: Click-based dual-curing thermosets and their applications. in 'Thermosets structure, properties, and applications' (ed.: Quo G.) Elsevier, Amsterdam, 511-577 (2017). https://doi.org/10.1016/B978-0-08-101021-1.00016-2 
[23] Russo C., Serra Á., Fernández-Francos X., De la Flor S.: Characterization of sequential dual-curing of thiolacrylate-epoxy systems with controlled thermal properties. European Polymer Journal, 12, 376-388 (2019). https://doi.org/10.1016/j.eurpolymj.2018.12.048

[24] Russo C., Fernández-Francos X., De la Flor S.: Rheological and mechanical characterization of dual-curing thiol-acrylate-epoxy thermosets for advanced applications. Polymers, 11, 997/1-997/16 (2019).

https://doi.org/10.3390/polym11060997

[25] Belmonte A., Lama G. C., Gentile G., Cerruti P., Ambrogi V., Fernández-Francos X., De la Flor S.: Thermallytriggered free-standing shape-memory actuators. European Polymer Journal, 97, 241-252 (2017) https://doi.org/10.1016/j.eurpolymj.2017.10.006

[26] Santiago D., Fabregat-Sanjuan A., Ferrando F., De la Flor S.: Recovery stress and work output in hyperbranched poly(ethyleneimine)-modified shape-memory epoxy polymers. Journal of Polymer Science Part B: Polymer Physics, 54, 1002-1013 (2016). https://doi.org/10.1002/polb.24004

[27] Xie T., Rousseau I. A.: Facile tailoring of thermal transition temperatures of epoxy shape memory polymers. Polymers, 50, 1852-1856 (2009).

https://doi.org/10.1016/j.polymer.2009.02.035

[28] Pascault J-P., Sautereau H., Verdu J., Williams R. J. J.: Thermosetting polymers. CRC Press, Boca Raton (2002). https://doi.org/10.1201/9780203908402

[29] Lakhera N., Yakacki C. M., Nguyen T. D., Frick C. P.: Partially constrained recovery of (meth)acrylate shapememory polymer networks. Journal of Applied Polymer Science, 126, 72-82 (2012).

https://doi.org/10.1002/app.36612
[30] Rapp S., Baier H.: Determination of recovery energy densities of shape memory polymers via closed-loop, force-controlled recovery cycling. Smart Materials and Structures, 19, 045018/1-045018/10 (2010). https://doi.org/10.1088/0964-1726/19/4/045018

[31] Arrieta J. S., Diani J., Gilormini P. J.: Cyclic and monotonic testing of free and constrained recovery properties of a chemically crosslinked acrylate. Journal of Applied Polymer Science, 131, 39813/1-39813/8 (2014). https://doi.org/10.1002/app.39813

[32] Ortega A. M., Yakacki C. M., Dixon S. A., Likos R., Greenberg A. R., Gall K.: Effect of crosslinking and long-term storage on the shape-memory behavior of (meth)acrylate-based shape-memory polymers. Soft Matter, 8, 7381-7392 (2012).

https://doi.org/10.1039/c2sm25298h

[33] Hashmi S. A. R., Prasad H. C., Abishera R., Bhargaw H. N., Naik A.: Improved recovery stress in multi-walledcarbon-nanotubes reinforced polyurethane. Materials and Design, 67, 492-500 (2015).

https://doi.org/10.1016/j.matdes.2014.10.062

[34] Fan J., Li G.: High enthalpy storage thermoset network with giant stress and energy output in rubbery state. Nature Communications, 9, 642/1-642/8 (2018).

https://doi.org/10.1038/s41467-018-03094-2

[35] Li A., Fan J., Li G.: Recyclable thermoset shape memory polymers with high stress and energy output via facile UV-curing. Journal of Materials Chemistry A, 6, 11479-11487 (2018).

https://doi.org/10.1039/C8TA02644K

[36] Belmonte A., Russo C., Ambrogi V., Fernández-Francos X., De la Flor S.: Epoxy-based shape-memory actuators obtained via dual-curing of off-stoichiometric 'thiol-epoxy' mixtures. Polymers, 9, 113-132 (2017). https://doi.org/10.3390/polym9030113 